\title{
MASSIVE OPEN ONLINE COURSES (MOOCS): IS IT REAL DEMOCRACY?
}

\section{Silvia Dell'Acqua}

European University Institute, Robert Schuman Centre for Advanced Studies

\begin{abstract}
Education. Democracy. These are two sides of the same coin: Society.
\end{abstract}

How can be a society, democratic, if it does not offer a sound education to its fellow citizens?

My central question is : Will the 'Digital Divide', in Higher Education, be filled, globally, by MOOCs? Or on the contrary, the claim "Anyone with an Internet connection can have access to Higher Education (i.e. MOOCs) is misleading, in reality? In my opinion the concept of 'access' needs to be interrogated carefully: it cannot just be assumed that because something exists and because it is 'free', it is then accessible to everybody globally. There are a variety of mitigating factors which limit access to MOOCs: the lack of the set of certain infrastructures - i.e. reliable electricity, unrestricted Internet connections -and resources - temporary or communal accommodation, rural communities, people relying on welfare or living on low incomes - can represent huge obstacles. Together with other factors, such as long working hours, multiple jobs, long distance travel from home to work.

My goal is to give a potential answer to these key questions, by investigating if MOOCs can be a new form of Democracy in Higher Education, globally.

Keywords: In Higher Education, Democracy

\section{Introduction}

\section{Education Democracy Society (EDS): the Global Triangle}

Education. Democracy. Society. The first and the latter are at the roots of the third. Both of them have changed over time, shaping themselves according to people, their history and the human environment they were "living" in. It is meaningful to use this verb for these concepts: Education pertains to human beings; more education means better conditions, equality of opportunities regardless of social backgrounds, the nature of mobility, 
within society, which can bring progress. Democracy has been attached to humans since ancient history. The extension of participation in decision taking and the deepness of the impact in the decision making have marked significantly the progress in the history of humanity. Qualitative and quantitative Education goes hand in hand with sound and live Democracy: Society benefits having both of them in good shape.

This stated, in order to make an assessment of the condition of both of them, one should make an analysis which would encompass the many aspects they both implies. That would be an endless exercise, and for sure, it would leave holes which could compromise the results and the conclusions one could draw. However, what a researcher can do, in order to investigate Society, and its facets, namely Education and Democracy, is to shed light on a particular aspect of this mare magnum.

In my paper, I will focus on Higher Education (H.E.) and the impact of Information and Communication Technologies (ICTs) on it. In particular I will investigate the last frontier of Massive Online Open Courses (MOOCs), as way of delivering academic content to the masses, and in particular to people who have not the possibility to attend University in the traditional way, and not only this, even more, interestingly, aiming to people who are not traditionally belonging to the University audience.

"Why an Indonesian, in his forties, cannot listen to a lecture by a Harvard Professor?” This is one of the core questions which led to the birth of MOOCs. Technologies help: they shorten distances, they lower barriers. This is true, in many ways, but also other considerations should drive changes: not only what can be, on the surface, democratic, it is as such, in reality. Accessibility, intended in many ways, - I will explain this aspect and infrastructures are fundamental variables to take into account. Namely, a high grade of accessibility does not correspond only to have a video of a MOOC online: will the person, on the other side of the word, be able to connect stably to the band? Will her or his level of the foreign language (English, French, German, Chinese etc) will enable her or him to understand the discourse? Will she or he be too tired in the evening to follow the lecture, perhaps having worked for two or three different jobs during the day, or having commuted or walk a long distance? Will the infrastructure help the '2.0 student' to follow the video, or he or she will watch it in bits and pieces? Will her or his culture will speak the same codes of the professor? Prerequisites will cut him or her off, making 'the student' thinking they are not up to the standards? Will she or he think "It is out of my league". These are not rhetorical questions, you can answer YES or NO according to the specific human and environmental setting you are referring to, in this paper I am, however, challenging the idea that what is "accessible" in principle, is "usable" in the substance, universally. The intentions of 
whom conceived, put together, and deliver MOOCs are for sure positive, this is not under doubt, what I am questioning in this paper is that pre-requisites, both of concrete and abstract nature, do matter and determine if inspiration and good intentions meet the high goals set from innovators. Revolutions in Education do not happen all of a sudden, Education is for its inner nature very much attached to culture, it speaks about traditions, it lies at people's human roots and belongs to intergovernmental sphere for the policy domain. Education is very much protected, it has barriers around, to preserve its contents and way in which it is delivered. Democratic sea-changes do not occur with a top-down approach, rather, common practices, transferable methods, innovative techniques, "educational positive virus" spread globally through bottom up logics. Thinking outside the boxes is fundamental: the world in which we live today is Glo-Cal, thinking of it only focusing either on the first or on the second component means to shed light only on one aspect; it brings mystification which could lead to disappointment, even to the most enlightened thinkers. Modern cultural colonialism can consist of sugar-coating Western contents, ways of teaching, visions and points of views assimilating them to a sort of human common sense which leads to think and act, consequently, having in mind this consideration: "Excellence is here. We reached it, this is un-doubtful - according the standards we have set - so now we can go, globally, to spread our verbum, since it is excellent. People will be grateful to us because we have made them part of our excellency, of our first class knowledge. We share what we have attained, making it accessible to people who cannot afford our education, because of the physical, psychological and social distance, but we are democratic, and we deliver it to you, no matter what”. It is, in some ways, abrupt but, in a nutshell this is the reasoning behind MOOCs, as they were initially intended.

I am not, in this paper, encompassing the cases in which MOOCs are promotional. That is a purpose that I am not taking into consideration MOOCs are investigated here as learning materials, which can be delivered to people globally, and whose unique goal is to share first class knowledge, with the intention to make it available for the masses all over the world (taking, already, for granted that everybody can access a computer, connected to the internet).

Above I have expressed, in a nutshell, my personal opinion on the MOOCs, and my doubts on their democratic real nature; hereafter I will provide a conceptual and policy framework, where to put my statements, in order to give evidence of what I am alleging.

The European Union, as a source of Democracy and Education will be my loading star, being the first pillar of theoretical construction, while digitalisation of society will be the second pillar, and Higher Education 
global evolution, in terms of methods, practices, contents, goals and audiences, will be the third one.

\section{Society Digitalisation and Higher Education Evolution: Exploring New Democratic Sources}

The central question of this paper is "Does it mean that if something is accessible, is it automatically at hand for everyone?"

Are there, instead, some specific variables to take into consideration, which can lead to a different conclusion: something can be accessible in principle, but in reality, the contingent human and situational constraints are obstacles which prevent its accessibility. In reality, what is accessible in principle can be, therefore, patrimony of some. Even if globalisation make us nearer to each other and more similar to each other in some respects, I would say more that our cultural differences can dialogue better one with the other having common framework: this does not mean that constraints are eliminated.

This concept can be applied to the state of Democracy in the European Union, tracing a parallel with Digitalisation of Society and of Higher Education in particular.

More specifically, in the last decade, we have assisted to interesting political phenomena: politics is more personal, it is more dealing with individuals, rather than ideas, it sublimates the leader, people often talk of one person or another rather than of ideas and programmes. Media are fundamental, both to mark and help the rise of a personality in the political spectrum, or to deteriorate his or her chances to succeed in his or her run to be elected: people watch the news, some read newspapers, others surf the web looking for information or videos to shape their opinion. Information are more accessible but, which kind of information are they? Will people discern and be able to choose among the different layers of news? Will the majority have the cultural and intellectual instruments to form their opinion in an informed way? Or the news are in principle accessible, but in reality only some will be able to get those information? Moreover, why elections' turnouts are decreasing in Europe and in the Western World, in general? Is Democracy, because considered accessible, and in a certain sense, taken for granted by its fellow citizens, belonging more and more, substantially, to closed circles who decide and dispose, since citizens are disappointed and are delegating more and more the principle of representation, at the highest level?

Again accessibility dos not mean real 'use' and active participation.

As J. Habermas puts out "We firstly need to know how we want to understand democracy. Democratic self-government means that addressees of mandatory laws are at the same time their authors. In a democracy, 
citizens are subjects only to those laws which they have given themselves in accordance with a democratic procedure. The legitimasing force of this procedure rests, on the one hand, on the inclusion of all citizens in the political decision-making processes and on the other, on the coupling of majority decisions with deliberative will-formation. Such a model of democracy transforms the citizens' use of communicative freedoms into as many productive forces for the legitimate self-influencing of a politically organised civil society. If the citizens are to be able to cooperate in influencing social conditions, then the state must have corresponding scope for the political shaping of living conditions." In this rests the sense of conceptual connection between popular sovereignty and state sovereignty. Moreover as R. Dhal points out when referring to democratic elections "Citizens who participate in a democratic election and who authorise a few to act on behalf of all certainly engage in a collective practice. But this transforms democratically generated decisions into decisions of a collective only in a distributive general sense". For these decisions are the product of a plurality of individual stances which are generated and processed in accordance with democratic rules.

Article 1 of the Universal Declaration of Human Rights, which was adopted by the United Nations on $10^{\text {th }}$ December 1948, begins with the statement: "All human beings are born free and equal in dignity and rights". We all should start, therefore, from the same conditions as we all belong to humanity, but this 'should' refer of course not to our human condition, but to what is attached to it: our social environment. This is what determines if accessible in principle, means accessible, in reality.

Democracy is globally accessible, their rituals, rules, frameworks and patterns of action are codified: the vote is the highest expression of it. But why, more and more, in Western society we are experiencing populism, disaffection and disappointment towards voting and politics? Democracy is, in numerous situations, ill and alone. It is accessible in principle but discarded by many who can have access to it. Why? Because you should have, as citizen, the perception of: how precious it is, where to access it, for which purpose to treasure it. If you have not this 'democratic prerequisites' then Democracy is something worth only to those who have the means to access it, and from universal becomes 'of some'.

Democracy is government of the people, by the people and for the people: but is it accessible in the same way and by the same means to everyone?

\section{An Array of Innovative Ways to Measure the Diameter of the World}

Making a step further, focusing on Societal Digitalisation, the parallel is self-evident: Information and Communication Technologies have made 
the diameter of the world in which we live shorter. It seems that we live the lives of people who are physically far from us, through devices which can shorten human distances, but, does this mean that in the neologism 'Glo-Cal' is the prefix 'Glo' which prevails?

The concept of 'digitalisation' belongs semantically to the sphere of Innovation. This has become a key concept in our society, transversal and universal per se, it does not stem only from research, and focuses, solely, on specific disciplines or sectors. As the European Institute of Innovation and Technology points out in the Report on Synergies: "Innovation is happening in new ways throughout the world, through the co-creation of knowledge, the development of business, user-led ideas and, more recently, societal challenge-led approaches." Innovation takes place on the one hand, through trans-national partnership building, multi-stakeholder, multi-disciplinary and multinational teams; and on the other supporting freedom of circulation of people and knowledge.

Innovation belongs, itself, to the semantic sphere of Knowledge, and to be real, it has to be coupled by 'sharing'. Production of knowledge means also dissemination and positive exploitation of it, globally, through ICTs. What is crucial in Digitalisation of Society is the optimal circulation, access to and transfer of scientific knowledge. Namely when scientists, research institutions, businesses and citizens (last but not the least) have the opportunity to access, share, discuss and use existing scientific knowledge the innovation system as a whole benefits. The Digital Agenda in Europe and world wide encompass the same principles: implementing Open Access (OA) i.e. free internet access for different purposes; fostering Open Innovation and knowledge transfer between public research institutions and the private sector; strengthening the knowledge triangle between research, business and education.

Knowledge pertains to Growth semantic sphere. It is becoming more and more a buzz word, given its positive inner meaning policy makers want to include it in every speech they do and to show everything they do brings it, but in real terms, how could Growth flourish and spring out from policies? Europe 2020 gives an answer: growth should be smart, through more effective investments in education, research and innovation; sustainable, thanks to a decisive move towards a low-carbon economy; and inclusive, with a strong emphasis on job creation and poverty reduction. The strategy is focused on five ambitious goals in the areas of employment, innovation, education, poverty reduction and climate/energy".

Narrowing the focus on one of the aspect of Growth, Education, and in particular Higher Education, many significant steps have been made towards the creation of a European Higher Education Area (EHEA) without borders (2010), with the policy meaning to promote citizens' mobility and 
employability and the continent's overall development, and its evolution, the ERA, European Research Area. Creation of knowledge and transfer of it are the two pillars of the ERA, which is a fundamental part itself of the EU, intended as knowledge based economy. In this respect one of the main concerns of the EU is to fill the 'knowledge gap' with the other knowledge based economies globally, in the past, The United States and Japan, nowadays BRICS, China, Russia and emerging economies. Each of them, through Education and in this paper will be taken into consideration H.E., export its Knowledge, which can bring Growth and Innovation, ICTs are instrumental in so doing, but, the central question is: top-down approaches pay off? Knowledge is transferable? Do Digital Universities represent sound evolution? Do they brig progress or are there an illusion? Is distance learning simply an evolution of the Academy globally? And the key question: Is it feasible to re-invent the Academy, globally?

\section{Massive Open Online Courses: a Global Case Study}

Answering to the above-questions is only possible by focusing on specific expressions of innovative forms that Higher Education generates: Massive Open Online Courses are a case in point.

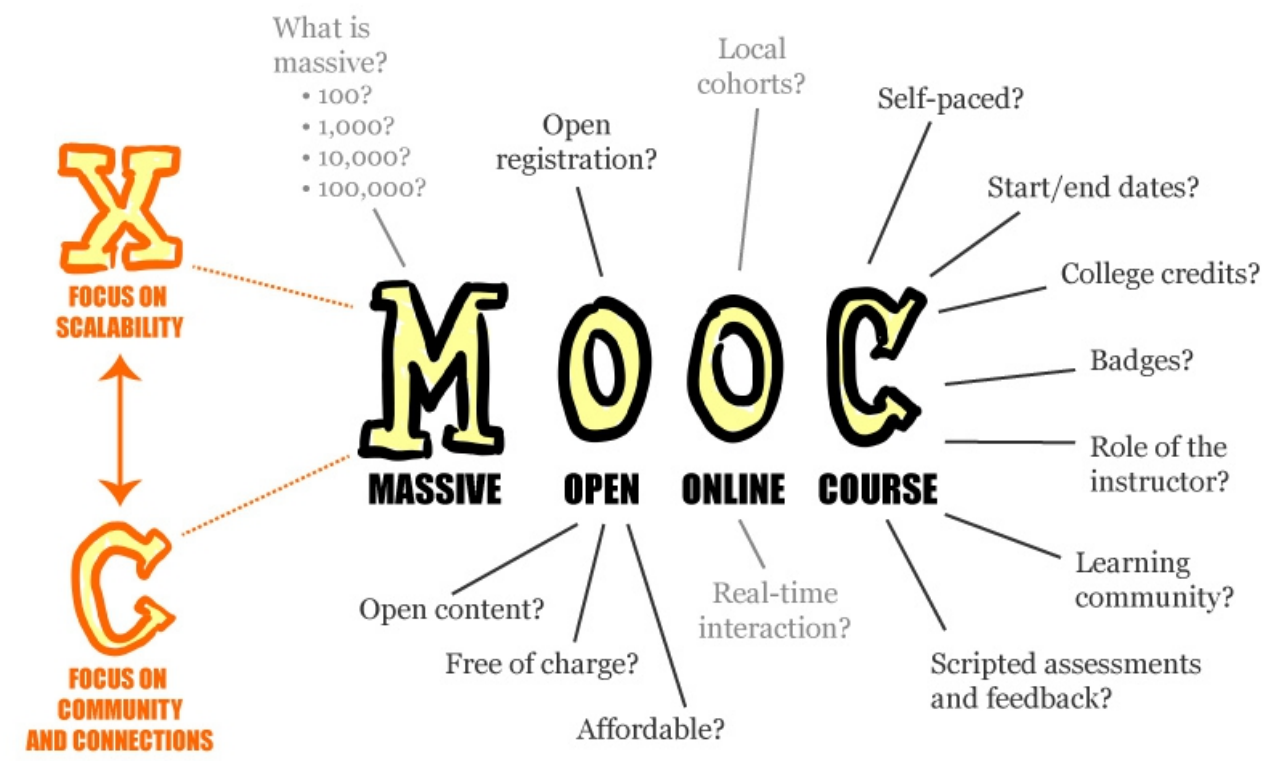

First of all I will provide here the universal definition of what a MOOC is: "A Massive Open Online Course is an online course aimed at unlimited participation and open access via the web. In addition to traditional course materials such as videos, readings, and problem sets, MOOCs provide 
interactive user forums that help build a community for students, professors, and teaching assistants (TAs). MOOCs are a recent development in distance education.” Although early MOOCs often emphasised open access features, such asconnectivism and open licensing of content, structure, and learning goals, to promote the reuse and remixing of resources, some notable newer MOOCs use closed licenses for their course materials, while maintaining free access for students. North American top Universities (i.e. courses: Udacity, Cousera), Latin American ones , European, Asian (Malaysia is a fore-runner), Australian Academic institutions have started to provide their e-audience with MOOCS. Stakeholders (both public entities and private ones -i.e. Iversity in Germany) are interested in the innovative process which can spring from this novelty: new partnerships are developed, private and public look at each other with interest, having in front of them a 'prairie', but what about students and professors? How does their role change?

A MOOC does not mean to look at a talking head in a video. It is far more than that. A MOOC means to re-invent the way of teaching and of learning radically.

First of all you have no more the personal relation with your professor and your colleagues (fora and peer-reviews are not substitutes); drop-outs are more frequent since personal engagement can be harmed by lack of commitment for different contingencies; difficulties encountered are faced by the student alone and these difficulties do not stem simply from notions themselves, but cultural differences matter as fundamental components - who is teaching in MOOC doe not know a priori who is the potential audience, therefore it is not possible to fine-tune with a class - in one word: standardisation is the fil-rouge, in a MOOC.

In my presentation I will show three MOOCs (the first from Europe, the second from the United States, the third from Asia) that I have personally singled out, because of their characteristics, comparing one to the other following eight guidelines/benchmarks: teaching style; techniques used; learning impact; technical means necessary to follow them; cultural references made; actors involved; kinds of follow up implied; level of connectedness and its implications.

\section{Conclusions}

Global Education through Information and Communication Technologies has a great potential to bring Innovation and Growth, by sharing Knowledge. Before alleging this syllogism, one should investigate case by case the most promising phenomena that Information and Communication Society propose to us. MOOCs are one of them, and according to what I have stated in this paper, also by tracing a parallel with the state of Democracy today, and to what I will show in the presentation by 
focusing on three kinds of MOOCs, the evolution of global Higher Education, rebus sic stantibus, is not at a point of maturation which can allow to state that MOOCs are an instrument of democracy. It is not sufficient giving the impression that high quality of knowledge is no more treasured in 'knowledge temples', by being online, therefore available to everyone. Real accessibility is the key variable to be taken into consideration, its level, now, has not reached yet the level by which real democracy start.

The future will tell if this benchmark will grow, in this case democratic-impact evaluation of Massive Open Online Courses will evolve accordingly. 